\title{
The importance of north-west Madagascar for marine turtle conservation
}

\author{
Jessica Metcalf, Katie Hampson, Alain Andriamizava, Rivo Andrianirina, Tom Cairnes, Anna Gray, \\ Claudine Ramiarisoa and Henriot Sondotra
}

\begin{abstract}
The coast of north-west Madagascar is an important nesting and feeding ground for marine turtles, but little is known about populations in this area. From July to December 2000 we documented nesting activity of, and investigated threats to, green Chelonia mydas and hawksbill Eretmochelys imbricata turtles at three sites along this coast: Nosy Iranja, the Radama Islands, and the Nosy Hara archipelago. Levels of nesting activity varied between sites, with green and hawksbill turtle nesting concentrated in different areas. The principal threats identified were opportunistic exploitation of
\end{abstract}

nesting females and incidental capture in fishing nets. Commercial importance of marine turtles was negligible, suggesting conservation measures such as targeted environmental education could have beneficial impacts on these populations. Evidence for high levels of nesting activity reported here indicate that education efforts in these areas should be a conservation priority.

Keywords Chelonia mydas, Eretmochelys imbricata, green turtle, hawksbill turtle, Madagascar, nesting, Nosy Hara.

\section{Introduction}

The longevity and complicated life cycle of marine turtles make them vulnerable to a multitude of threats. Five of the world's seven marine turtle species are found in the coastal waters of Madagascar (Rakotonirina \& Cooke, 1994); the island is reported to host important foraging and nesting populations (Hughes, 1973; Frazier, 1975; Rakotonirina \& Cooke, 1994) and has a long history of marine turtle exploitation for domestic use and international trade (Hughes, 1973; Frazier, 1980). The most recent published review estimated the total annual marine turtle catch in Madagascar at 15,000

Jessica Metcalf' (Corresponding author) and Katie Hampson ${ }^{2}$ St Hugh's College, Oxford, OX2 6LE, UK. E-mail cjm29@duke.edu

Alain Andriamizava Lot III R 28 A Tsarafaritra-Tsimbazaza-101, Antananarivo, Madagascar.

Rivo Andrianirina Departement de Biologie, Université d'Antananarivo, Ankatso, Madagascar.

Claudine Ramiarisoa and Henriot Sondotra Institut Halieutique et de Sciences Marines, Toliara, Madagascar.

Tom Cairnes 3 Broomground, Winsley, Bradford on Avon, BA15 2JT, UK.

Anna Gray 51 Bridge Street, Wye, Ashford, Kent, TN25 5ED, UK.

${ }^{1}$ Current address: Duke University, Box 90328, Durham, NC 27708, USA.

${ }^{2}$ Current address: Department of Ecology \& Evolutionary Biology, Princeton University, NJ 08544-1003, USA

Received 11 April 2005. Revision requested 16 September 2005. Accepted 23 January 2006.
(Rakotonirina \& Cooke, 1994) and suggested that this may exceed replenishment by Madagascar's apparently sparse nesting populations. Management of marine turtle populations in Madagascar is therefore of regional concern. It is important to identify nesting beaches and document exploitation patterns to contribute to national and regional management plans (Hughes, 1995). The project reported here attempted to respond to these needs. It focused on north-west Madagascar, along coastline stretching from the Radama Islands to Nosy Hara (Fig. 1). Four turtle species are reported from this area: green Chelonia mydas and hawksbill Eretmochelys imbricata turtles, categorized respectively as Endangered and Critically Endangered on the IUCN Red List (IUCN, 2006), both of which are reported to nest in north-west Madagascar (Humphrey \& Salm, 1996), and the loggerhead Caretta caretta and olive ridley Lepidochelys olivacea turtles, both categorized as Endangered (Rakotonirina \& Cooke, 1994; IUCN, 2006). We present results on the distribution of nesting sites for green and hawksbill turtles and report levels of exploitation for all marine turtle species encountered along these coasts.

\section{Study area}

We surveyed $115 \mathrm{~km}$ of beach in north-west Madagascar, focusing on three island groups and adjacent mainland (Fig. 1): (1) Nosy Iranja is a small island known to be a site of importance for nesting turtles and laws banning the capture of marine turtles there have existed since 1923 (Rakotonirina \& Cooke, 1994); from the early 1990s the 


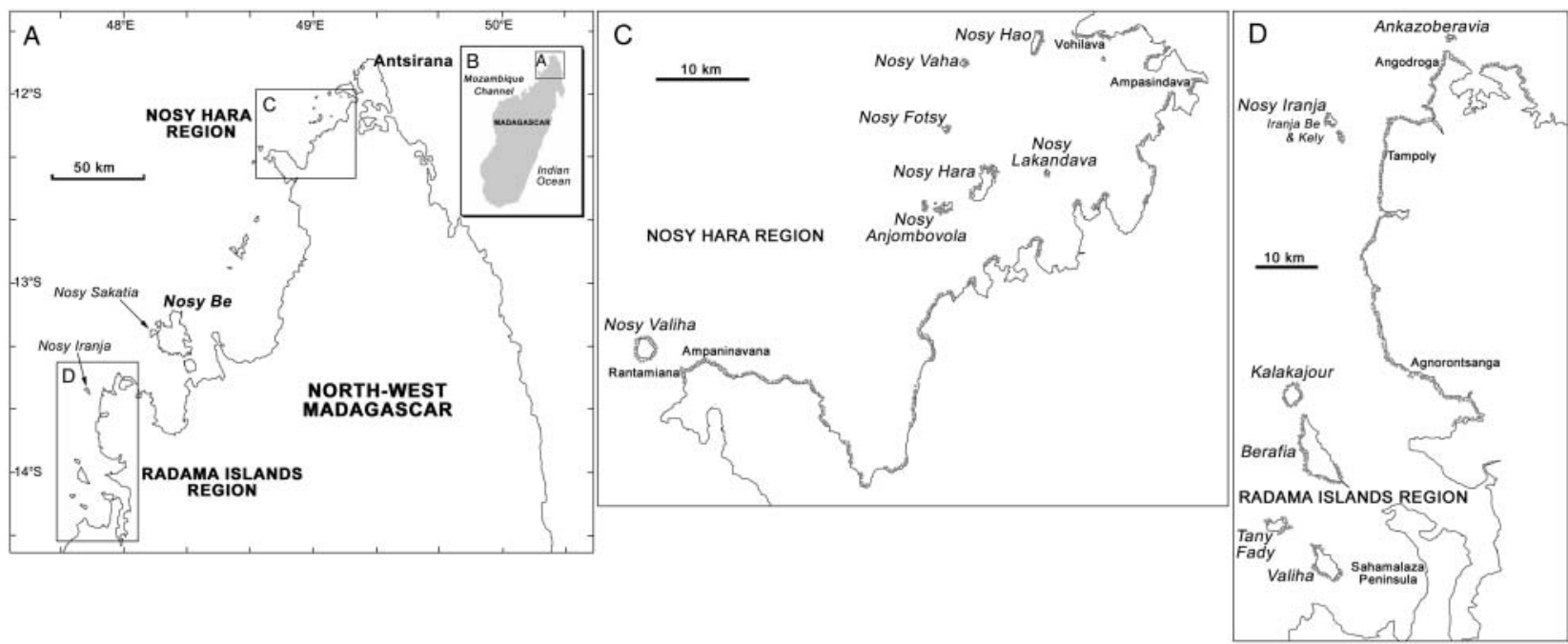

Fig. 1 Location of study sites in north-west Madagascar (A), with location in Madagascar shown in inset B. The rectangles in A are the Nosy Hara region (C) and the Radama islands and Nosy Iranja (D). In (C) and (D) islands labelled in italics have suitable nesting beaches (marked by grey dots). Important mainland beaches (also marked by grey dots) are always opposite important nesting islands: in the Nosy Hara region, Ampaninavana and Rantamiana are opposite Nosy Valiha; in the Radama Islands region, Angodroga is near the island of Ankazoberavia, and Tampoly is on the mainland opposite Nosy Iranja.

island was developed as a hotel complex. (2) The Radama Islands, Valiha, Berafia, Tany Fady, and Kalakajour, are inhabited, and used predominantly for agriculture; marine resource use is minimal except for commercial exploitation of fish and sea cucumbers by migrant fisherman based around Tany Fady. (3) The Nosy Hara archipelago is uninhabited, has extensive coral reefs and has been reported as important for nesting and foraging marine turtles (Commission Nationale pour 1'UNESCO, 1997). Marine resources are the main source of livelihood for two villages on the nearby mainland.

\section{Methods}

\section{Assessment of nesting activity}

From July to December 2000 we visited beaches in each site to assess nesting activity. Each beach was surveyed only once. Beach length and month of visit are given in Table 1. Number of body pits was recorded and density of body pits per $\mathrm{km}$ of coastline surveyed was calculated (Mortimer \& Day, 1999). Body pits are craters c. $0.5 \mathrm{~m}$ deep, excavated by turtles while nesting, although they do not always result in egg deposition (Schroeder \& Murphy, 1999). Identification of a body pit may be subjective; consequently one researcher (A. Andriamizava) undertook all counts to ensure consistency. Differences in diameter and depth (Mortimer \& Day, 1999) and known preferences in nesting site characteristics such as surrounding vegetation and sand type (Schroeder \& Murphy, 1999), in particular hawksbill preference for nesting under vegetation, were used to discriminate between body pits of green and hawksbill turtles. We assumed nesting by loggerhead and olive ridley turtles to be negligible, in line with previous reports (Rakotonirina \& Cooke, 1994).

Using body pit number and density as an index of nesting activity assumes the time frame over which body pits accumulate and persist is similar across beaches, which was not necessarily the case. Persistence depends on weather conditions and species' characteristics (J.A. Mortimer, pers. comm.). Nesting activity is also seasonal. Local inhabitants at all sites described a restricted nesting period for hawksbill turtles (as in the Seychelles; Mortimer, 1984) starting in January. Green turtles in the Western Indian Ocean nest throughout the year, although with seasonal variation (Mortimer, 1984). Nevertheless, the index provides a first approximation.

We monitored $1.9 \mathrm{~km}$ of beaches on Nosy Iranja for nesting turtles nightly from July to October 2000, and intermittently from September to December 2000 in the Nosy Hara region. Stockbrand titanium tags (with the prefix MAL followed by a four-digit number and the return address: BP 1348, Tana, WWF Madagascar) were applied to the trailing edges of both front flippers of nesting turtles, and curved carapace length (CCL) was measured. Efforts were made to minimize disturbance to nesting turtles, following Balazs (1999).

\section{Assessment of exploitation}

Along all beaches surveyed complete carapaces were measured and counted, as were skulls with no appropriately-sized carapace nearby. Incomplete remains 
were disregarded. Carapace number and density were used as indices of exploitation. This assumes the timeframe of carapace accumulation is similar across beaches, which was not necessarily the case. However, the measure provides an estimate of exploitation intensity. Carapace measurements of dead turtles were compared to those of nesting females. The relationship between exploitation intensity and nesting activity was investigated using Spearman's rank correlation, relating numbers of carapaces and body pits. We conducted semi-structured informal interviews with residents and migrant fisherman to determine which turtle species were present (using illustrations from Pritchard \& Mortimer, 1999), whether and how they were caught, and their socio-economic value. Fishing practices were assessed by direct observation.

\section{Results}

\section{Nesting activity}

Nesting activity is summarized in Table 1. Green turtle nesting activity levels were higher than those of hawksbill turtles. However, the latter may have been underestimated because hawksbill body pits are smaller and therefore less enduring, and their peak nesting activity according to local reports is in January, after our survey period. Most nesting by green turtles occurred on islands in the Nosy Hara region (69\%), with $42 \%$ on two islands (Nosy Valiha and Nosy Hao). Densities were highest on islands in the Nosy Hara and Nosy Iranja regions. Although not directly part of this survey, one beach on the island Nosy Sakatia (off Nosy Be, Fig. 1) was also known to be important, with 45 green turtle nesting events recorded over 26 nights and a high body pit density (Sagar, 2001). Highest numbers of hawksbill turtle nesting were recorded on the mainland off Nosy Hara and the Radama Islands, but densities were low. The islands Nosy Valiha and Nosy Hara had the next highest body pit numbers. Ankazoberavia, Nosy Lakandava, Nosy Hara, and Nosy Fotsy had the highest densities.

Most nesting activity occurred on islands. The percentage of the absolute number of body pits that were located on the mainland was sometimes high, but the distance that had to be covered to observe the same number of pits was always substantially less on islands. All the important mainland nesting beaches were adjacent to islands with high levels of nesting. No evidence of nesting was found on 74 apparently suitable (sandy, accessible) beaches (with a total length of $58 \mathrm{~km}$ ). Nearly half of these were adjacent to villages. Residents identified as important the same nesting beaches we identified through body pit counts, and corroborated the most abundant species identified.
From July to November 200017 green and four hawksbill turtles were tagged, 18 during nesting, and three hawksbill turtles obtained from fishermen who had caught them in nets were also tagged (Fig. 1). For comparison, in a parallel study, from January to March 200114 green turtles were tagged on Nosy Sakatia (Sagar, 2001). Green turtle nesting occurred from early evening through the night; hawksbill nesting was exclusively diurnal.

\section{Exploitation}

Carapaces of green and hawksbill turtles were found throughout the region (Table 1). Olive ridley turtle carapaces were found in the Nosy Hara region (two) and off the Radama Islands (three). Skulls of loggerhead turtles were found in the Radama Islands (one) and the Nosy Hara region (three). A loggerhead bearing a South African tag caught near Nosy Be was held at the Centre National de Recherches Oceaniques, Nosy Be. Another tag retrieved in the Nosy Hara region was from the Seychelles.

Carapace and body pit numbers per beach were positively correlated across all sites for green (Spearman's rank correlation $\mathrm{n}=121, \rho=0.59, \mathrm{P}<0.001)$ and hawksbill turtles ( $\mathrm{n}=121, \rho=0.43, \mathrm{P}<0.001)$. Measurements of green turtle carapaces suggested that most exploited animals were of reproductive age (Fig. 2). CCL of hawksbill turtles was $35-115 \mathrm{~cm}$. The three tagged hawksbill turtles recovered from fishermen were all juveniles (CCL $<60 \mathrm{~cm}$ ). Ten of the 27 beaches (with a total length of $22 \mathrm{~km}$ ) with evidence of exploitation but not nesting were next to villages where fishing was the main activity. Forty-seven beaches (with a total length of $36.2 \mathrm{~km}$ ) had neither carapaces nor body pits, despite appearing suitable for nesting.

Local informants reported that marine turtles were killed incidentally in nets (wide-meshed nets, jarifa, often $>100 \mathrm{~m}$ long, are used for shark fishing), opportunistically when ascending beaches, and by hand and harpoon from boats. For the local Sakalava ethnic group eating turtle is fady, or taboo, confirmed by numerous interviewees and the unwillingness of children to handle turtle remains, and also noted by Hughes (1973). However adherence to fady has declined and lucrative fisheries have attracted large migrant populations, many from ethnic groups not bound by such taboos. Green turtle meat was favoured, but hawksbill turtles were also eaten despite known food poisoning cases.

\section{Site summaries}

Radama Islands Tany Fady was the temporary base for large-scale commercial fishing, principally for shark fins and sea cucumbers destined for the Asian market. Marine turtles were not actively sought but we observed 


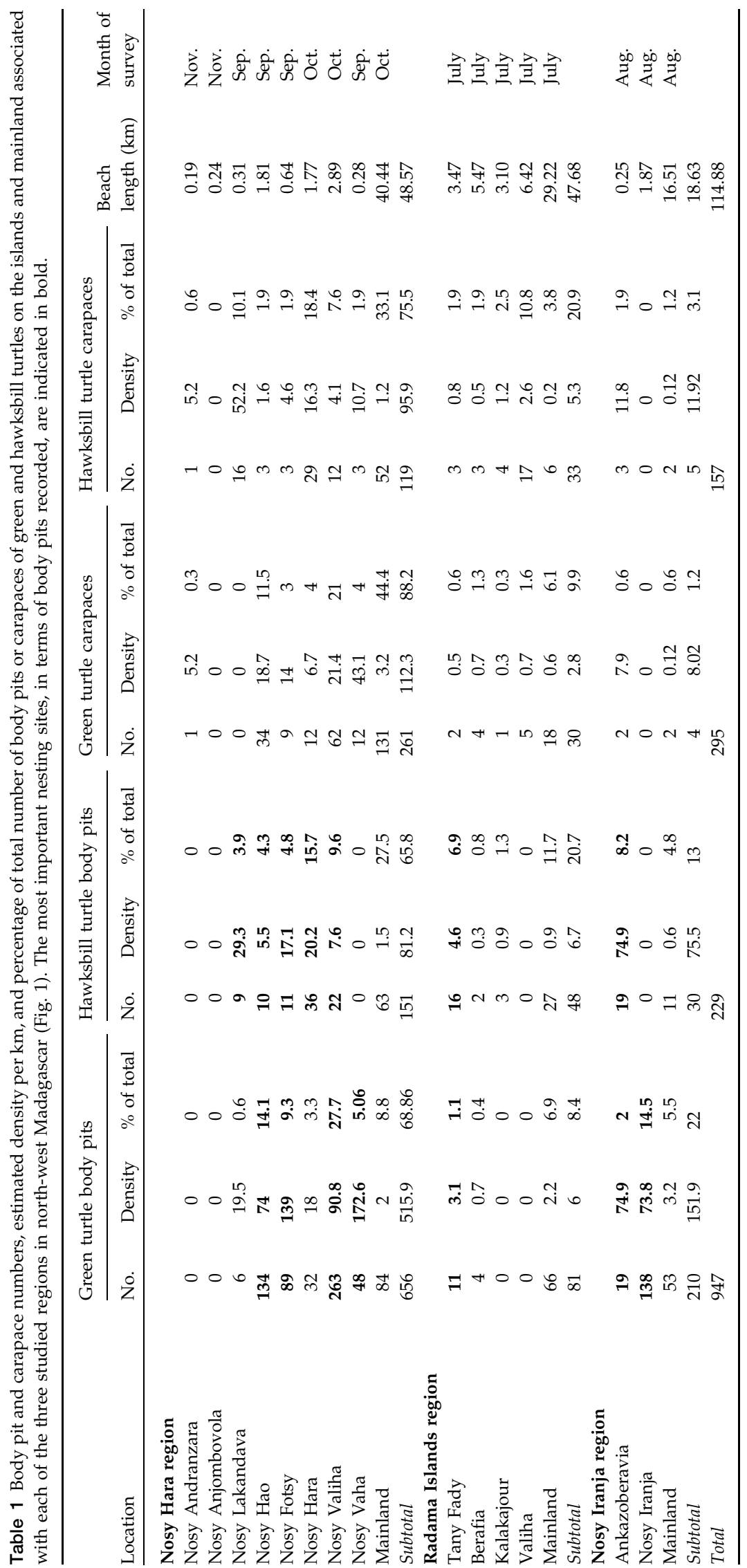




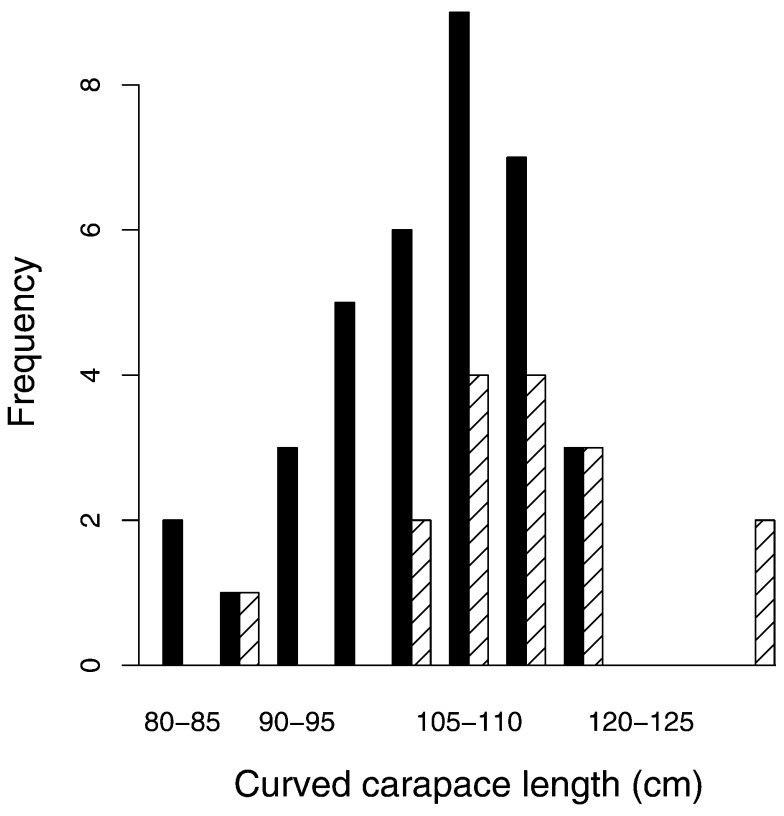

Fig. 2 Histograms of curved carapace length of green turtles: nesting females (hashed) and depredated carapaces (black) recorded during the study. The two distributions are significantly different (t-test: $\mathrm{n}_{1}=36, \mathrm{n}_{2}=16, t=2.54, \mathrm{P}=0.01$ ) indicating that both nesting females and juveniles are hunted.

at least one turtle in each day's catch. Carcasses were generally discarded rather than used or sold, and no active markets for meat or scutes were apparent (sale of scutes is illegal under Malagasy law). Little opportunistic exploitation of nesting females was reported, and few carapaces and body pits were observed on the other islands, which were predominantly agricultural. However, hawksbill scutes were found occasionally on the mainland and Valiha, the only site where islanders reported actively seeking hawksbill turtle scutes.

Nosy Iranja region Two fresh green turtle remains and possible evidence of nest predation was discovered despite previous surveys suggesting little exploitation (C. Ramiarisoa, unpubl. data.). However, relative to mainland beaches, exploitation was low and tourism is probably a deterrent.

Nosy Hara region Turtles were mainly captured whilst nesting or as by-catch from intensive shark fishing. Turtles were also opportunistically captured by hand or harpoon from the large seagrass beds and coral reef adjacent to Vohilava, the main fishing village. Vohilava had the most carapaces (67) recorded for any beach in the study.

\section{Discussion}

No work has been carried out in the region since the survey described here but, barring radical changes, our results indicate that important populations of green and hawksbill turtles nest along the coastline of north-west Madagascar. Similar levels of nesting activity were recorded using identical methodology in the Chagos archipelago in the Indian Ocean, a site considered of global significance for nesting hawksbill and green turtles (Mortimer \& Day, 1999). Although we cannot make population estimates based on our data, from a crude extrapolation (based on similar extrapolations from the Chagos archipelago; Mortimer and Day, 1999) we suggest 100-500 hawksbill and 700-1,200 green turtles may nest annually along the $115 \mathrm{~km}$ of coastline surveyed. This may be an underestimate, as good nesting habitat is known to exist along the lengthy coastline and numerous offshore islands located between our study sites.

Snorkeling and boat journeys undertaken during the course of the project indicated presence of suitable foraging habitat in this part of north-west Madagascar, including large shallow expanses of coral reefs and seagrass. Loggerhead, olive ridley, and leatherback turtles (reported as far north as Nosy Be), and green and hawksbill turtles migrating from rookeries elsewhere in the western Indian Ocean may forage here. In support of this, Hughes (1995) reports recaptured turtles in northwest Madagascar that were tagged in South Africa, Tromelin and Europa, and we recovered tags from the Seychelles and South Africa. Additionally, hawksbill (particularly juveniles) and green turtles are frequently captured (as are other species) in these potential foraging areas, which are the focus of sea cucumber and shark fisheries. We therefore suggest that in addition to the fact that north-west Madagascar may harbour regionally, perhaps globally, important nesting populations of Endangered green turtles and Critically Endangered hawksbill turtles, the foraging areas may also have regional significance.

Our results indicate exploitation in this area was chiefly opportunistic and highlight the importance of the Nosy Hara archipelago for conservation of these species. Although it was the windiest region (and therefore subject to most rapid beach erosion) it had most body pits and fresh carcasses of nesting females were regularly found at important nesting beaches. Along with previous results (Rakotonirina \& Cooke, 1994), this suggests impacts of current exploitation levels are high.

There was a strong correlation between nesting activity and exploitation, suggesting that capture during nesting is a key threat. Most nesting now occurs on uninhabited islands or inaccessible beaches, probably as a direct consequence of exploitation and habitat degradation (Rakotonirina \& Cooke, 1994). Hawksbill scutes were collected, although not extensively, throughout the areas surveyed. However, we found no locally active 
markets. Decline of this market since the large-scale hawksbill exploitation of the 19th century (Hughes, 1973) may be explained by a crash of the hawksbill turtle population, or perhaps economic isolation of Madagascar in the late 1980s driven by internal policies curtailed the once flourishing trade. Stricter conservation injunctions (including Madagascar becoming a signatory to the Nairobi Convention for the Protection, Management and Development of the Marine and Coastal Environment of the Eastern African Region in 1985, ratifying CITES in 1981, and becoming a party to the Convention on Biological Diversity in 2004) and changing attitudes towards buying turtle products also may have played a role.

Local people were interested in our research, open to discussions about conservation, and knowledgeable regarding turtle biology. Nonetheless, most were sceptical about the threatened status of marine turtles given their apparent abundance locally. Fishermen who would release hawksbill turtles refused to release the more palatable green turtles. An education project could be useful in explaining the situation regarding turtles in a wider temporal and spatial context. There is still considerable trade in turtle products even though it is illegal and therefore tourists, who are the chief purchasers, should also be targeted for conservation education.

For effective conservation of turtles in north-west Madagascar, areas that combine evidence of high levels of nesting activity and exploitation should be prioritized for protection. Focusing conservation efforts on Nosy Valiha and Nosy Hara in the Nosy Hara archipelago would encompass almost $31 \%$ of green turtle and $25 \%$ of hawksbill estimated nesting activity, although the combined sites represent only $2 \%$ of the beach distance covered by our survey. Exploitation was high, but its generally opportunistic nature suggests that targeted conservation education programmes may prove successful.

In 2001 the Nosy Hara archipelago and the Radama Islands were named as candidate protected areas, with emphasis on protection of marine resources. A joint ministerial decree agreed in January 2005 provides temporary protection to the Radama Islands and a drive to extend its status to a National Park is being led by the Wildlife Conservation Society. The Nosy Hara region does not yet benefit from any protection but a dossier requesting temporary protection has been submitted to the appropriate ministerial authorities by WWF.

\section{Acknowledgements}

We thank the Comission Tripartite of the Malagasy Government (Organization Nationale de l'Environnement,
Association National pour la Gestion des Aires Protégées, and Départment des Eaux et Forêts) and local communities for permissions, our sponsors (the BP Conservation Programme, Oxford University Exploration Club, Quest International, The North of England Zoological Society and the Royal Geographical Society), our collaborators (WWF Madagascar, Jina Sagar, Andrew Cooke, Jean-Paul Paddack, Remi Ratsimbazafy, Matthew Hatchwell, Fred Faure, Lalao Randriambilatra, Institut Halieutique et des Sciences Marines, Université de Toliara, and Université d'Antananarivo), and our advisors, Jeanne Mortimer, Nancy Fitzsimmons and Clive Hambler. We are grateful to Daniel Bennett and five anonymous referees whose comments greatly improved this paper. Both the Wildlife Conservation Society and WWF gave advice on this project and were provided with a complete report.

\section{References}

Balazs, G.H. (1999) Factors to consider in the tagging of sea turtles. In Research and Management Techniques for the Conservation of Sea Turtles (eds K.L. Eckert, K.A. Bjorndal, F.A. Abreu-Grobois \& M. Donnelly), pp. 101-109. IUCN/Species Survival Commission Marine Turtle Specialist Group Publication No. 4, Washington, DC, USA.

Commission National pour l'UNESCO (1997) Atelier d'identification de sites potentiels pour une reserve de biosphere marine a Madagascar. Unpublished Report, UNESCO, Antananarivo, Madagascar.

Frazier, J. (1975) Marine turtles of the Western Indian Ocean. Oryx, 13, 162-175.

Frazier, J. (1980) Exploitation of marine turtles in the Western Indian Ocean. Human Ecology, 8, 329-370.

Hughes, G.R. (1973) The survival situation of the hawksbill sea-turtle (Eretmochelys imbricata) in Madagascar. Biological Conservation, 5, 114-118.

Hughes, G.R. (1995) Conservation of sea turtles in the South African region. In Biology and Conservation of Sea Turtles, Revised Edition (ed. K.A. Bjorndal), pp. 397-405. Smithsonian Institution Press, Washington, DC, USA.

Humphrey, S.L. \& Salm, R.V. (eds) (1996) Status of Sea Turtle Conservation in the Western Indian Ocean. UNEP Regional Seas Reports and Studies No. 165, IUCN/UNEP, Nairobi, Kenya.

IUCN (2006) 2006 IUCN Red List of Threatened Species. IUCN, Gland, Switzerland [http://www.redlist.org, accessed 12 October 2006].

Mortimer, J.A. (1984) Marine Turtles in the Republic of the Seychelles: Status and Management. IUCN, Gland, Switzerland.

Mortimer, J.A. \& Day, M. (1999) Sea turtle populations and habitats in the Chagos Archipelago. In Ecology of the Chagos Archipelago (eds C.R.C. Sheppard \& M.R.D. Seaward), pp. 159-176. Westbury Academic and Scientific Publishing, Otley, UK.

Pritchard, P.C.H. \& Mortimer, J.A. (1999) Taxonomy, external morphology, and species identification. In Research and Management Techniques for the Conservation of Sea Turtles (eds K.L. Eckert, K.A. Bjorndal, F.A. Abreu-Grobois \& M. Donnelly), pp. 21-40. IUCN/Species Survival Commission Marine Turtle Specialist Group Publication No. 4, Washington, DC, USA. 
Rakotonirina, B.P. \& Cooke, A. (1994) Sea turtles of Madagascar - their status, exploitation and conservation. Oryx, 28, 51-61. Sagar, J.P. (2001) Ecology and Conservation of Sea Turtles in the Nosy Be Islands, Madagascar. Unpublished Report, WWF, Madagascar.

Schroeder, B. \& Murphy, S. (1999) Populations surveys (ground and aerial) on nesting beaches. In Research and Management Techniques for the Conservation of Sea Turtles (eds K.L. Eckert, K.A. Bjorndal, F.A. Abreu-Grobois \& M. Donnelly), pp. 45-55. IUCN/Species Survival Commission Marine Turtle Specialist Group Publication No. 4, Washington, DC, USA.

\section{Biographical sketches}

Jessica Metcalf's interests include evolution, and the conservation of Malagasy herpetofauna. She is currently working on senescence. Katie Hampson's interests are in population dynamics, conservation and development. She currently works on rabies ecology in Tanzania. Alain Andriamizava is currently working as an environmental consultant and plans to start a thesis on turtle migration patterns. Henriot Sondotra is completing a $\mathrm{PhD}$ on marine pollution. Rivo Andrianirina and Claudine Ramiarisoa are completing diplomas in marine resource management and conservation. Tom Cairnes' current research interests include private equity in post-conflict economies. Anna Gray recently completed an MSc in Tourism, Environment and Development. 